\title{
Coisas sérias e muito verdadeiras
}

\author{
Rui Pina Coelho
}

Titulo: Velocidade máxima. Direç̧ão: John Romão. Dramaturgia: Mickael de Oliveira. Espaço cénico: Diego Beyró e John Romão. Colaboração coreográfica: Elena Córdoba. Desenho de luz: Daniel Worm d'Assumpção. Desenho de som: Jorge Pina. Videos: Carlos Conceição e John Romão. Interpretação: John Romão, André, Leandro e Luis. Pianista: Cláudia Teixeira. Produção: Colectivo 84 / Festival Citemor, La Laboral, Murmuriu, Penetrarte e ZDB. Local e data de estreia: Sala B, Festival Citemor, Montemor-o-Velho, 8 de Agosto 2009.

Titulo: Às vezes as luzes apagam-se. Direç̧ão artistica: Cláudia Varejão e Pedro Gil. Espaço cénico: Pedro Silva. Música original: Bruno Pernadas. Design de luz: José Álvaro Correia. Desenho vídeo: Paulo Américo. Interpretação: Beatriz Pessoa, Daniel Duarte, Duarte Águas, Filipa Silva, Mariana Meireles, Marta Fatela, Nuno Cerqueira, Simão Lamas, Wilma Brito. Produção: CCB, Fábrica das Artes, Festival Temps d'Images. Local e data de estreia: Pequeno Auditório do Centro Cultural de Belém, Lisboa, 29 de Outubro de 2009.

Titulo: 0 que se leva desta vida. Autores: Gonçalo Waddington, João Canijo e Tiago Rodrigues. Encenação: Gonçalo Waddington e Tiago Rodrigues. Dramaturgia: João Canijo. Colaboração artística: Thomas Walgrave. Interpretação: Gonçalo Waddington e Tiago Rodrigues. Produção: Mundo Perfeito e SLTM e. Local e data de estreia: S. Luiz Teatro Municipal, Lisboa, 6 de Novembro 2009.

0 teatro documentário é um teatro de reportagem

Peter Weiss (2008: 382)

Em meados dos anos sessenta, obras como 0 caso Oppenheimer (In der Sache J. Robert Oppenheimer, 1964), do dramaturgo alemão Heinar Kipphardt, ou A investigação (1965), de Peter Weiss, - respectivamente, uma dramatização do processo de condenação pública do físico nuclear Robert Oppenheimer por suspeita de filiações comunistas; e uma peça-documentário criada a partir de julgamentos de guardas nazis de Auschwitz, realizados em Frankfurt, - inscreviam-se num subversivo "Teatro dos Factos", género com uma clara agenda de interpelação e contestação dos valores estabelecidos e das verdades oficiais. No entender de David Edgar, dramaturgo também ele próximo destas coordenadas ideológicas, esta estratégia de utilização de documentos por contraponto à "invenção dramática" era uma atitude deliberada. Assim:

Os dramaturgos estavam a afirmar que, depois das monstruosidades de Auschwitz e Hiroshima, os velhos conceitos de causa e efeito já não se aplicavam. Tudo o que o dramaturgo poderia fazer seria apresentar os documentos ao público para que este pudesse fazer deles o que quisesse. (Edgar 2008)

Nesse sentido, e conclui Edgar, o "Teatro dos Factos era o outro lado da moeda do absurdismo dos anos cinquenta e sessenta. Ambos expressavam fenómenos que eram incapazes de explicar" (ibidem) ${ }^{2}$. Peter Weiss, em "Notas sobre o teatro contemporâneo" (1971), define o teatro documentário em catorze itens, texto que ainda hoje ajuda a entender a praxis do documentário na contemporaneidade. No primeiro item afirmava:

\begin{abstract}
0 teatro documentário é um teatro de reportagem. Registos de tribunal, dossiês, cartas, dados estatísticos, boletins do mercado de valores, relatórios de corporações financeiras e empresariais, declarações dos governos, discursos, entrevistas, declarações de personalidades públicas, jornais e rádios, fotografias, reportagens jornalisticas ou outros documentos da vida contemporânea fornecem os alicerces para o espectáculo. (Weiss 2008: 382)
\end{abstract}

Por estas linhas se explica o ressurgimento que formas anti-miméticas, - tais como o teatro documental ou verbatim, espectáculos com não-actores ou peças criadas a partir de factos ou eventos reais - assumiram nos últimos anos. Como bem identifica Janelle Reinelt, explicando algumas das razões para o ressurgimento do documentário enquanto forma popular, este deve-se à "crescente consciência da distorção dos factos por agentes oficiais ["spin"]; [e à] incapacidade da imprensa e do jornalismo em explicar acontecimentos públicos complicados" (Reinelt 2009: 12). Estas circunstâncias levam inevitavelmente a uma quebra da confiança nas narrativas institucionais. Ainda segundo Reinelt: "o apetite pelo documentário pode sinalizar um aumento do desejo pelo contacto com aqueles 'traços da presença de um passado real' num mundo verdadeiro de incertezas indecifráveis" (Reinelt 2009: 13).

Embora esta situação não seja social e civicamente agradável, teatralmente é muitíssimo apelativa. E a confusão epistemológica que se cria entre o real e o ficcionado, o autêntico e o construído, tem sido uma área muito cara a alguma da criação contemporânea. Como argumenta o professor e crítico alemão Hans-Thies Lehmann:
Esta e outras traduções quando não identificadas de outro modo nas referências bibliográficas são da minha autoria. 0 mesmo acontece com títulos de peças e de espectáculos que não mereceram ainda tradução portuguesa.

2 Argumentos também apresentados e desenvolvidos no artigo de David Edgar publicado no número 10 (Dez. 2008) desta revista: "Do sangue e sémen às cadeiras e bancadas: A nova dramaturgia britânica dos anos noventa e de agora", pp.61-67. 

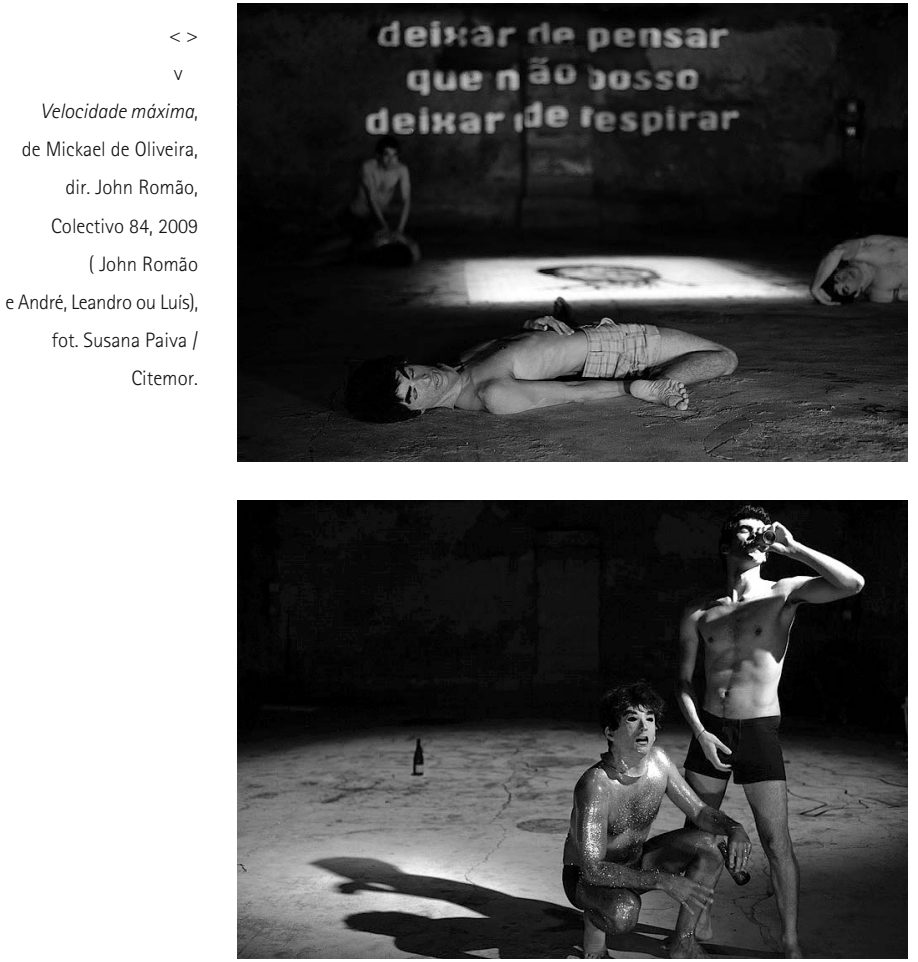

Quando a prática cénica força os espectadores a duvidar se devem reagir aos eventos no palco como ficção (i.e. esteticamente) ou como realidade (por exemplo, moralmente), o estilhaçar da fronteira entre o real e o teatral vem inquietar esta predisposição decisiva dos espectadores: a irreflectida certeza e segurança de que a experiência que vivem enquanto espectadores se trata de um comportamento social não problemático. (Lehmann 2006: 104)

Os três espectáculos aqui em análise trabalham precisamente sobre esta zona: Velocidade máxima, de John Romão e Mickael de Oliveira, Ás vezes as luzes apagam-se, de Cláudia Varejão e Pedro Gil e O que se levo desta vida, de Gonçalo Waddington, João Canijo e Tiago Rodrigues. E todos convocam e confundem factos reais com narrativas ficcionadas, todos misturam realidade com performance e todos inspiram um cruzamento entre 0 autêntico e o simulado. Três dos intérpretes de Velocidade máxima são prostitutos masculinos brasileiros e 0 espectáculo assenta em grande parte nas suas narrativas pessoais; em Ás vezes as luzes apagam-se assistimos a diversas histórias de vida contadas na primeira pessoa por nove adolescentes; 0 que se leva desta vida ficciona o dia-a-dia de uma parelha de cozinheiros, espectáculo criado a partir da observação in loco em várias cozinhas e restaurantes. Como se afigura óbvio, cada um inscrevese de maneira diferente no mapa maior do teatro documental. Situação que não causará perplexidade se considerarmos as palavras do teórico de cinema Bill Nichols:

Os documentários não adoptam um inventário fixo de técnicas, nem tomam um determinado conjunto de temas, nem apresentam um restrito conjunto de formas e estilos. Nem todos os documentários partilham um determinado número de caracteristicas. (Nichols apud Reinelt 2009: 7)

Ainda assim, Carol Martin, num artigo intitulado "Bodies of Evidence", publicado num número da revista TDR

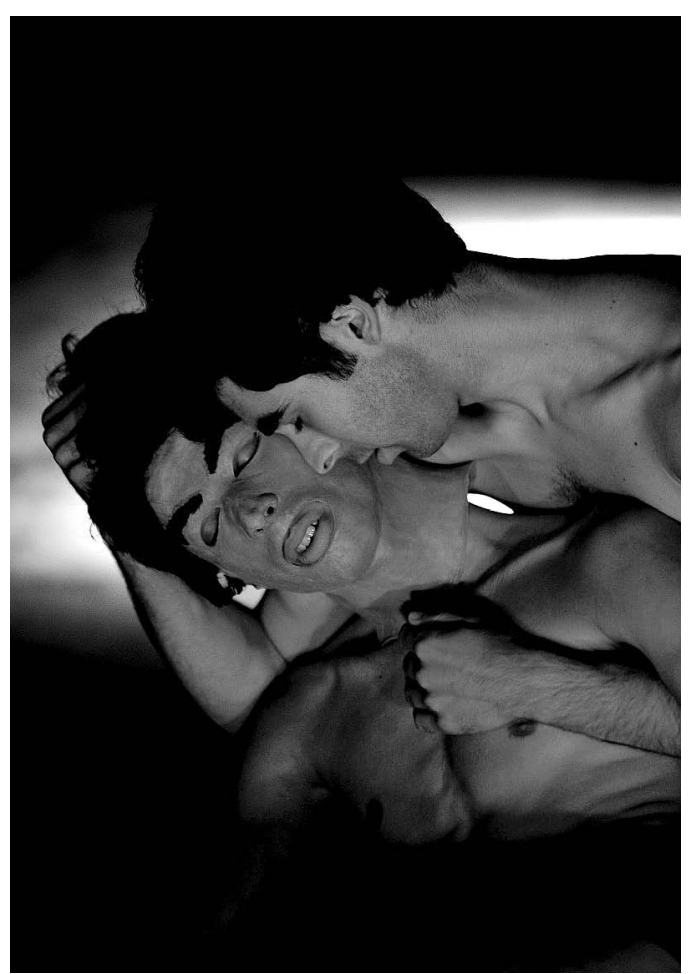

dedicado ao teatro documentário (Outono 2006), lista seis possíveis funções deste género na contemporaneidade:

'1. Reabrir julgamentos no sentido de criticar a justiça'; '2. Criar testemunhos históricos complementares'; '3. Reconstruir um acontecimento'; '4. Cruzar autobiografia com história'; '5. Criticar as operações quer do documentário quer da ficção'; '6. Trabalhar sobre a cultura oral do teatro'. (Martin 2006: 12,13)

E os três espectáculos em discussão inscrevem-se nesta cartografia (em especial, se quisermos especificar, nos pontos 2, 4, 5 e 6). Ou seja, relatam histórias pessoais inscrevendo-as num tempo histórico preciso, o que resulta numa discussão pública sobre o modo como a sociedade se organiza, ao mesmo tempo que problematizam a especificidade da experiência dramática.

Velocidade máxima integra o ciclo "Posse e Poder" do Colectivo 84, constituido por espectáculos interessados num "imaginário e espaço experimental e conceptual que destaca o corpo enquanto linguagem, a sexualidade enquanto língua, e a questão da moralidade e dos limites, assim sendo, da representação" (no sítio do grupo em http://colectivo84.blogspot.com). Este singular colectivo (um intérprete/director, um dramaturgo e duas produtoras, Ágata Alencoão e Lara Silveira) tem trabalhado com um universo eminentemente documental: em $70 \mathrm{Kg}$ o intérprete era um skater que aos 18 anos foi vítima de um acidente tendo sido atingido por uma coluna de 70 quilos; na recriação do mito de Hipólito, contracenava com John Romão uma criança, num espectáculo que es(x)piava os escândalos da Casa Pia; em Só os idiotas querem ser radicais utiliza-se a figura de um belo e jovem actor (Ângelo Rodrigues) para tratar da mercantilização da cultura e do feio na arte. Estreado na sala B do Citemor sala de paredes escamadas e arruinadas, o perverso Velocidade máxima socorria-se das narrativas pessoais de três prostitutos masculinos para criar um discurso sobre 


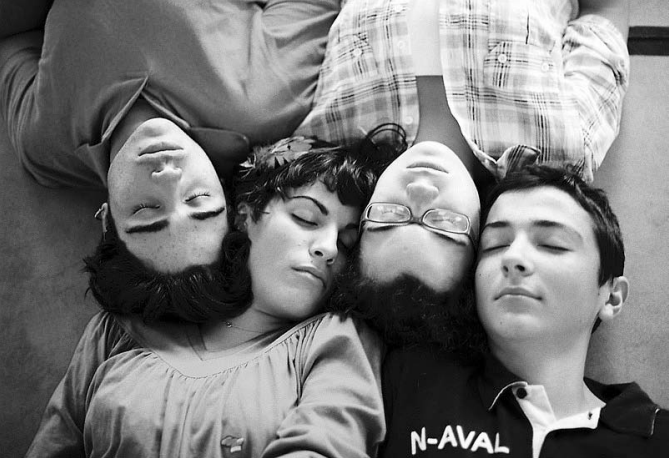

a prostituição na arte e na vida e sobre a virgindade artística. No prólogo do espectáculo (que peca somente por não ter uma explícita consequência dramatúrgica nas restantes cenas) John Romão apresenta-se como jovem criador, expõe o balancete financeiro da produção do espectáculo e, sobretudo, queixa-se da falta de oportunidades, do mercado da arte, dos programadores, da crítica, da vida. Oscilando entre um tom declaradamente infantil e um estilo ardilosamente irónico, Romão inscrevia aquele exercício de cena na sua própria vida e ficava desde logo instalada a confusão entre a verdade e a ficção de todo o aparato. Este discurso sobre a arte é depois ampliado com a presença dos três prostitutos que, usando máscaras com a cara do artista-director-intéprete, vão contanto as suas histórias. Para esta narração na primeira pessoa usam as suas próprias palavras e idiossincrasias de linguagem, mas usam também, disseminadas por todo o texto, as frases eruditas e artificiosas de Mickael de Oliveira (originais, reescritas a partir de excertos de outros autores, como Nietzsche, por exemplo, ou de relatos dos intérpretes).

Ainda que por vezes o tom do espectáculo estivesse perto de uma certa esfera melodramática, no que esta tem de hiperbolização de emoções (aspecto sublinhado pela presença de um pungente piano e pela agonia de alguns episódios), o tom geral era de miscigenação entre o real e o ficcionado, entre o entrevistador e os entrevistados. Velocidade máxima é também palco para algumas cenas de antologia: uma coreografia estupenda e minimal com os intérpretes deitados no chão apenas movendo as nádegas; uma suposta chamada telefónica entre um dos intérpretes e um cliente, jogada em playback; o diálogo em que Romão, mostrando revistas de teatro a um dos intérpretes e dando o exemplo do espectáculo de Jan Fabre, Orgie de la Tolérance, tenta convencer um dos actores a enfiar a bandeira da União Europeia no ânus diálogo pleno de duplos sentidos e que sinalizava a temática da imigração e da clandestinidade bem como a grandeza do gesto artístico; a projecção do texto "O meu dever é o de limpar a França com um canhão de água, dizia Sarkozy. E eu digo: Devíamos limpar as ruas de brasileiros / revolucionários / ciganos / bonitos / polícias / chineses / punks / paneleiros / flores / sangue/ Velocidade máxima" enquanto a parede onde este é projectado é limpa, precisamente, por um jacto de água - gesto poeticamente fútil; e a sequência vídeo em que Romão entrevista na cama um dos prostitutos, numa explícita homenagem à vídeo-instalação "Voracidade Máxima" da dupla de artistas Dias \& Riedweg, um trabalho que discute a intima relação entre identidade, imigração, economia e prostituição através da projecção de diversas entrevistas a profissionais

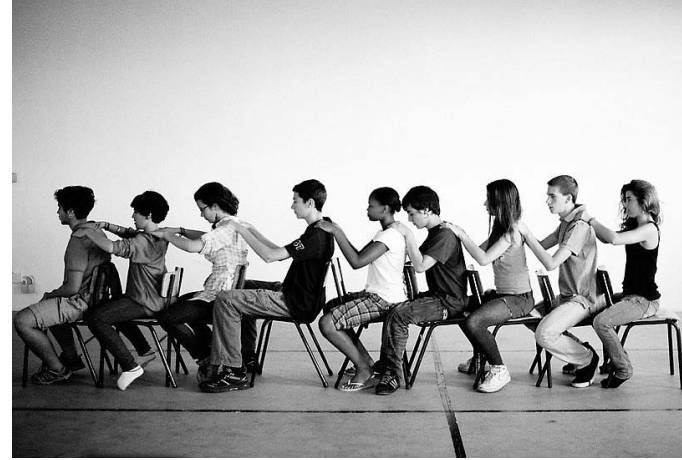

do sexo de origem sul-americana e que esteve na génese da criação do espectáculo.

Do trash de Velocidade máxima, o espectáculo Ás vezes as luzes apagam-se tem muito pouco. Com efeito, é um espectáculo assente num dispositivo cénico depurado, limpo e cuidado. No palco aparecem diversos objectos que indicavam quartos de adolescentes: camas, mesas, candeeiros e outros objectos que sinalizavam interiores domésticos e familiares. Contudo, a cena era dominada pelos enormes ecrãs onde eram projectados vídeos caseiros, entrevistas, bem como outros materiais documentais. Apresentado como um "concerto performativo", que acumulava quadros narrativos sem uma evolução dramática, antes derivativa, este espectáculo tinha como ponto de partida a adolescência:

Retrato do quotidiano de pessoas, provenientes de diferentes estratos sociais, com idades compreendidas entre os 14 e os 18 . 0 pensar demais, os pequenos e os grandes segredos, o corpo que se tem e aquele que se gostava de ter, os medos, as dúvidas, as primeiras vezes, os sonhos, os pais separados e os pais casados, a escola, os amigos, a noite, a música e o sorriso quando se fala sobre aquela pessoa[.] (Cláudia Varejão e Pedro Gil no programa do espectáculo)

Estes eram os ingredientes principais de um espectáculo que misturava dispositivos formais provenientes do cinema cruzando-os com os das artes performativas. 0 resultado, sendo estética e formalmente muito encantador, deixava a ideia de que os entrevistados-objectos de estudo-intérpretes conseguiam apropriar-se de todo o mecanismo de criação para criar versões easy-listening das suas próprias vidas. Ou seja, uma vez que as estratégias narrativas passavam essencialmente pelo auto-retrato e pela autobiografia estas eram utilizadas no sentido de mostrarem exclusivamente narrativas "oficiais", apelando à simpatia do público. Criava-se uma falsa ilusão de verdade que o dispositivo cénico não conseguiu desmontar de maneira a que os materiais produzidos pelos intérpretes não esmagassem o propósito documental do projecto. "Trata-se de um espectáculo documental na mesma medida em que um realizador filma um documentário ou um encenador concebe uma peça a partir de dados reais de pessoas reais e os transpõe para a cena", escreviam os responsáveis pela direcção do espectáculo no programa. Mas poderíamos inquirir sobre o grau de autenticidade das narrativas apresentadas ou sobre a dimensão da ficção ali construída. Ou seja, em vez de se ampliar o universo explorado (a adolescência), reduziase ao imaginário individual dos seus intérpretes (os adolescentes) - o que não é forçosamente mau, não fosse o declarado fulgor documental do projecto.
Ás vezes as luzes apagam-se, dir. Cláudia Varejão e Pedro Gil, CCB / Fábrica das Artes / Festival Temps d'Images, 2009 (> Nuno, Filipa, Marta e Daniel; v Nuno, Filipa, Marta Daniel, Wilma, Simão, Mariana, Duarte, Beatriz) foto de ensaio de Cláudia Varejão. 
O que se leva desta vida

de Gonçalo Waddington,

João Canijo e Tiago

Rodrigues, Mundo

Perfeito/SLTM, 2009

(> Tiago Rodrigues,

Gonçalo Waddington

e Bruno Canas),

fot. José Frade.

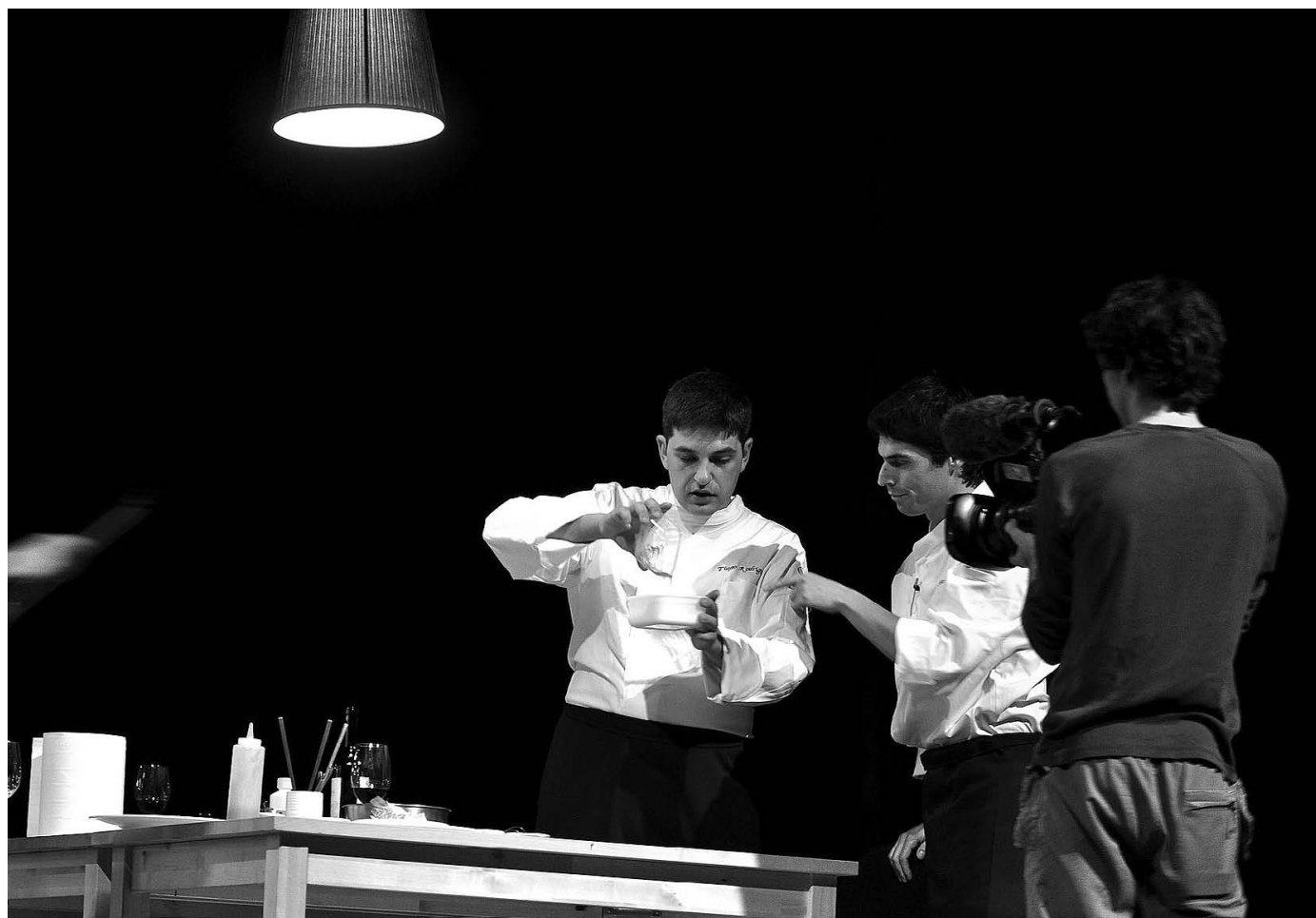

Ainda assim, o espectáculo era de uma depuração estilistica irrepreensível e na articulação do performativo com o visual, brilhantemente concebido. Jogado com grande acerto por todos os jovens actores, ali foram revelados amores, sonhos, ambições, particularidades, desejos para o futuro, excertos de diários, álbuns de familia passatempos e preferências, fotos e vídeos de familiares e amigos. Em suma, (apenas) a face visivel das histórias de vida de nove adolescentes.

O que se leva desta vida namora com uma outra forma de convocar o real. De uma inteligência matemática, era um espectáculo que espantava pela simplicidade. Em palco surgia uma cozinha onde seis cozinheiros confeccionavam verdadeiros pratos, exalando apetitosos e inevitáveis odores; e uma mesa onde os dois chefs iam comendo, conversando e maltratando os seus colaboradores, assim denunciando as assimetrias sociais presentes numa cozinha.

0 espectáculo simula a realização de um documentário sobre dois famosos cozinheiros que são proprietários do restaurante lisboeta de alta-cozinha "Cópia" - o chefTiago Rodrigues e o chef Gonçalo Waddington. Assim, as identidades dos actores são confundidas com as das personagens. Com efeito, há sequências textuais que evocam acontecimentos reais da biografia dos intérpretes e na sala estava um cardápio (como o de um qualquer restaurante) onde se podia ler uma biografia ficcionada para cada um dos chefs. A confusão era explícita e deliberada. 0 dispositivo do documentário com a captação de imagens em tempo real e projectadas em dois grandes plasmas, um de cada lado do palco, parodiava também os populares programas televisivos de cozinha ou formatos como o da série The Office (criada por Rick Gervais), onde também se simula a realização de um documentário.

Esta estratégia, além de ser bastante divertida, revelava-se como o mecanismo necessário para que a singela metáfora do espectáculo - falavam de cozinha, de alimentos e das diferentes maneiras de os confeccionar, mas falavam realmente da criação artística e da vida - fosse consequente e eficaz. E para isso os seus executantes não podiam ser mais apropriados. Assim, se um cozinheiro é pela adaptação do cozinhar ao alimento, o outro é pela repetição da receita: um é pelo táctil, o outro é pelo mental; um é pelo prazer da vida, o outro pelo prazer das ideias. Também os criadores Gonçalo Waddington e Tiago Rodrigues são artistas radicalmente diferentes. Waddington tem sido um actor de composição, densidade e presença; Rodrigues é exímio na transparência, na narração e no distanciamento. E por isso mesmo, o espectáculo ganhava uma outra tessitura, habitando aquela zona híbrida e colorida da verdade e da mentira.

Em suma, são três espectáculos que atestam o ressurgimento e a diversidade do interesse documental na cena contemporânea e que vão inventando novas maneiras de cruzar o real com o ficcionado.

\section{Referências bibliográficas}

EDGAR, David (2008), "Doc and Dram", The Guardian, 27 de Setembro 2008

-- (2008), "Do sangue e sémen às cadeiras e bancadas: A nova dramaturgia britânica dos anos noventa e de agora", trad. Rui Pina Coelho, Sinais de cena, n. 10 (Dez. 2008), pp.61-67.

FORSYTH, Alison / MEGSON, Chris, (2009), Chris, Get Real:Documentary Theatre Past and Present, London, Palgrave and Macmillan.

LEHMANN, Hans-Thies (2006), Postdramatic Theatre, Trans. Karen JürsMunby, London and New York (1999).

MARTIN, Carol (2006), "Bodies of evidence", TDR- The Drama Review: Documentary Theatre. Vol. 50:3 (T 191), Outono 2006, pp.8-15.

REINELT, Janelle (2009), "The Promise of Documentary" in FORSYTH e MEGSON 2009: 6-23.

WEISS, Peter (2008), "Notes on the Contemporary Theatre" in David Krasner (Ed.), Theatre in Theory 1900-2000: An Anthology, Oxford, Blackwel Publishing Ltd, pp.381-386 (1971) 